\title{
Intraoperative endoluminal pyloromyotomy as a novel approach to reduce delayed gastric emptying after pylorus-preserving pancreaticoduodenectomy - a retrospective study
}

\author{
Matthias C. Schrempf ${ }^{1}$ (D) David R. M. Pinto ${ }^{1} \cdot$ Johanna Gutschon $^{1} \cdot$ Christoph Schmid $^{2} \cdot$ Michael Hoffmann $^{1}$. \\ Bernd Geissler $^{1}$ - Sebastian Wolf ${ }^{1} \cdot$ Florian Sommer $^{1} \cdot$ Matthias Anthuber $^{1}$
}

Received: 21 August 2020 / Accepted: 1 October 2020 / Published online: 14 October 2020

(C) The Author(s) 2020

\begin{abstract}
Background Delayed gastric emptying (DGE) is one of the most common complications after pylorus-preserving partial pancreaticoduodenectomy (ppPD). The aim of this retrospective study was to assess whether an intraoperative pyloromyotomy during ppPD prior to the creation of duodenojejunostomy reduces DGE.

Methods Patients who underwent pylorus-preserving pancreaticoduodenectomy between January 2015 and December 2017 were divided into two groups on the basis of whether an intraoperative pyloromyotomy was performed (pyloromyotomy (PM) group) or not (no pyloromyotomy (NP) group). The primary endpoint was DGE according to the ISGPS definition. The confirmatory analysis of the primary endpoint was performed with multivariate analysis.

Results One hundred and ten patients were included in the statistical analysis. Pyloromyotomy was performed in 44 of $110(40 \%)$ cases. DGE of any grade was present in 62 patients (56.4\%). The DGE rate was lower in the PM group (40.9\%) compared with the NP group (66.7\%), and pyloromyotomy was associated with a reduced risk for DGE in univariate (OR 0.35, 95\% CI 0.16$0.76 ; P=0.008$ ) and multivariate analyses (OR $0.32,95 \%$ CI $0.13-0.77 ; P=0.011$ ). The presence of an intra-abdominal complication was an independent risk factor for DGE in the multivariate analysis (OR 5.54, 95\% CI 2.00-15.36; $P=0.001)$.

Conclusion Intraoperative endoluminal pyloromyotomy during ppPD was associated with a reduced risk for DGE in this retrospective study. Pyloromyotomy should be considered a simple technique that can potentially reduce DGE rates after ppPD.
\end{abstract}

Keywords Pylorus-preserving pancreaticoduodenectomy $\cdot$ Delayed gastric emptying $\cdot$ Pyloromyotomy $\cdot$ Pancreatic cancer

\section{Introduction}

Partial pancreaticoduodenectomy $(\mathrm{PD})$ is the standard treatment for resectable tumors of the pancreatic head, the ampulla of Vater, and the distal common bile duct. In the 1970s, Traverso et al. [1,2] introduced a pylorus-preserving modification (ppPD) which has been shown to be equally effective compared with the classical PD with regard to long-term survival and tumor recurrence. In-hospital mortality rates are less

Matthias C. Schrempf

matthias.schrempf@uk-augsburg.de

1 Department of General, Visceral and Transplant Surgery, University Hospital Augsburg, Stenglinstrasse 2, Augsburg 86156, Germany

2 Department of Hematology and Oncology, University Hospital Augsburg, Stenglinstrasse 2, 86156 Augsburg, Germany than $5 \%$ in high-volume centers, but perioperative morbidity remains high for PD and ppPD $[3,4]$. One of the most common complications after either PD or ppPD is delayed gastric emptying (DGE) with an incidence of up to 61\% [5]. Although DGE is not a lethal complication, it is associated with longer hospital stay, higher costs, and reduced quality of life $[6,7]$.

In 1985, Warshaw and Torchiana [8] first described DGE after PD. In 2007, the International Study Group of Pancreatic Surgery (ISGPS) proposed a definition and a grading system based on clinical parameters in order to standardize the term DGE which had been inconsistently defined by various authors [9]. The ISGPS definition represents the most widely accepted definition today.

While mild DGE usually resolves without further treatment, severe DGE may require noninvasive or invasive treatment. Commonly used treatments for DGE include gastric decompression via nasogastric tube, parenteral nutrition, use 
of prokinetics, and interventional treatment $[10,11]$. The practices vary widely between institutions, and evidence is low.

The etiology of DGE remains largely unknown. Intraabdominal complications such as anastomotic leakage, pancreatic fistula, and formation of hematoma or abscess are associated with a higher incidence of DGE in several studies $[10,12-14]$. Therefore, the occurrence of DGE in the absence of intra-abdominal complications has been referred to as "primary DGE" by some authors in order to distinguish cases of DGE with and without accompanying intra-abdominal complications [5].

DGE has been attributed to spasm of the pyloric muscle, devascularization of the pylorus, and postoperative hormonal changes, although the underlying mechanisms remain poorly understood [15-19].

Numerous studies investigated modifications of the surgical procedure including the route of reconstruction, pyloric dilatation, and pyloric resection and their impact on DGE with conflicting results [5, 15, 20-24]. Larger randomized trials and meta-analyses using the ISGPS definition were unable to show an association between the investigated modification of the procedure and DGE $[5,20,21,25]$.

Under the assumption that pyloric spasm or dysregulation plays a role in the development of postoperative DGE, we added an intraoperative endoluminal pyloromyotomy during ppPD for some of our patients. In this retrospective study, we provide a description of the technique and present our initial experience.

\section{Methods}

This study was conducted at the Department of General, Visceral and Transplant Surgery at University Hospital Augsburg, Germany, as a single-center retrospective study with a superiority hypothesis (intraoperative pyloromyotomy is associated with less DGE compared with no intraoperative pyloromyotomy). The study was approved by the Ethics Committee of Ludwig Maximilian University (LMU), Munich (reference number 17-620UE), and conducted in accordance with the Declaration of Helsinki.

\section{Study population and definitions}

We identified all patients who underwent pylorus-preserving pancreaticoduodenectomy irrespective of the underlying diagnosis at our institution between January 2015 and December 2017 from the institutional electronic database. Electronic health records were reviewed, and perioperative data were extracted. Complications, comorbidities, operative data, and patient characteristics were collected from the database, including age at the time of surgery and sex. All operative reports were reviewed, and patients were divided into two groups according to the intraoperative handling of the pyloric muscle: those who underwent intraoperative pyloromyotomy (pyloromyotomy (PM) group) prior to the creation of the duodenojejunostomy and those who did not receive intraoperative pyloromyotomy (no pyloromyotomy (NP) group).

The ISGPS definition of DGE was applied for this study [9]. DGE grade A was present if the nasogastric tube (NGT) was still in place or reinserted between postoperative days (POD) 4 and 7 or if the patient was unable to tolerate a solid oral diet by POD 7. Patients suffered from grade B DGE if the NGT was still in place or reinserted between POD 8 and 14 or if patients were unable to tolerate a solid oral diet by POD 14 . If the NGT was still in place or reinserted after POD 14 or if patients were unable to tolerate a solid diet by POD 21, DGE was assessed as grade $\mathrm{C}$ in accordance with the ISGPS definition. The Clavien-Dindo classification [26] was used for grading of complications. The presence of a postoperative pancreatic fistula (POPF) was diagnosed by lipase measurements from the fluid output via intra-abdominal drains, or if lipase measurements were not performed, a clinical diagnosis was made by the surgeon in charge based on the appearance of drain fluids. The grading of the POPF (biochemical leak, grade $\mathrm{B}$ or C) was done in accordance with the 2016 update of the ISPGS definition of POPF [27].

\section{Description of surgical technique}

The standard surgical procedure was a pylorus-preserving PD. The duodenum was divided into 2 to $4 \mathrm{~cm}$ distal to the pylorus. Pancreaticojejunostomy and hepaticojejunostomy were performed using end-to-side anastomoses. Prior to the creation of the duodenojejunostomy, one of two different surgical maneuvers was routinely performed at the discretion of the surgeon in charge. An intraoperative endoluminal pyloromyotomy was performed using electrocautery to transect the mucosa, the submucosa, and the circular pyloric muscle anteriorly and posteriorly at the 12 and 6 o'clock positions (Fig. 1), or if pyloromyotomy was not performed, a Gross-

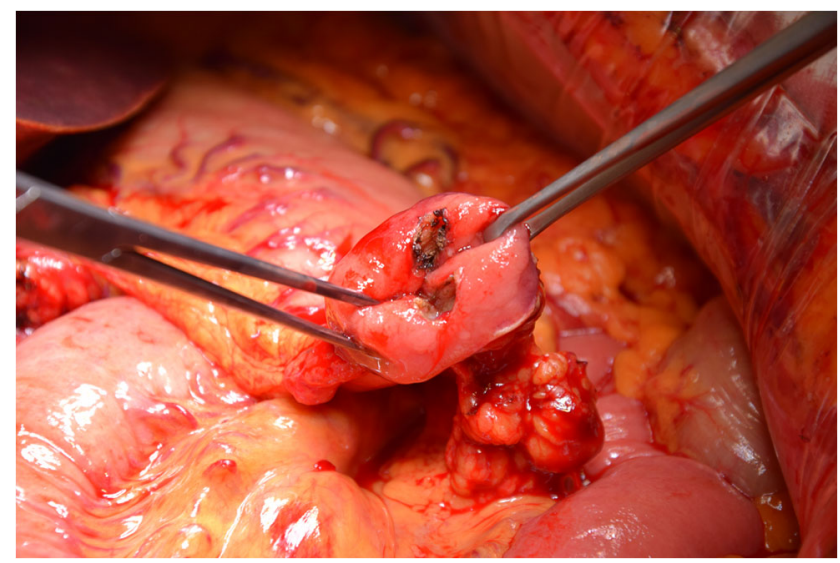

Fig. 1 Intraoperative endoluminal pyloromyotomy 
Maier dressing forceps was used to apply atraumatic multidimensional stretching to the pyloric muscle prior to the creation of duodenojejunostomy. In all patients, reconstruction was performed with an omega loop in an antecolic fashion and a side-to-side Braun jejunojejunostomy approximately $15 \mathrm{~cm}$ distal to the duodenojejunostomy. Based on the internal standard, subcutaneous octreotide at a dose of $100 \mu \mathrm{g}$ was administered intraoperatively at the time of the creation of the duodenojejunostomy and octreotide injections were continued three times daily until postoperative day 4 .

\section{Endpoints}

The primary endpoint was the rate of DGE as defined by the ISGPS in the PM and NP groups.

Secondary endpoints were the DGE grade, length of hospital stay, in-hospital mortality, and rate of postoperative complications.

\section{Statistical analysis}

Continuous data is presented as mean \pm standard deviation or median with interquartile range, depending on the distribution. Categorical data is presented as numbers with percentages. Approximately normally distributed continuous variables were compared using the independent $t$ test. Nonnormally distributed continuous variables were compared using the Mann-Whitney $U$ test. Categorical data was compared using the $\chi^{2}$ test. Fisher's exact test was used for categorical data when the requirements for the $\chi^{2}$ test were not met. A two-sided $P<0.05$ was considered significant. Baseline characteristics (age, BMI, sex, chronic renal insufficiency, diabetes mellitus, previous abdominal surgery, malignant disease, ASA III or higher) and early postoperative intraabdominal complications (chyle leak, intra-abdominal fluid collection, pancreatic fistula, and the presence of at least one complication arising from an intra-abdominal focus) were tested for potential association with DGE in univariate analysis. Risk factors with a potential association $(P<0.15)$ with DGE in univariate analysis and risk factors which had shown an association with DGE in multivariate analysis of prospective studies (BMI, POPF, sex, benign pathology, intraabdominal complication) $[10,13,20,28]$ were included in multivariate analysis. The confirmatory analysis of the primary endpoint was performed with multivariate analysis (binary logistic regression) including all risk factors with potential association with DGE $(P<0.15)$ and risk factors which had shown an association with DGE in multivariate analysis of prospective studies. Statistical analyses were undertaken using SPSS ${ }^{\circledR}$ for Windows ${ }^{\circledR}$, version 24 (IBM, Armonk, NY, USA).

\section{Results}

Between January 2015 and December 2017, a total of 114 patients underwent ppPD without vascular reconstruction at our institution. Four patients were excluded from the analysis. One patient was excluded because he had undergone choledochojejunostomy previous to ppPD, and three patients were excluded because of incomplete documentation. All operations were performed by a total of nine surgeons.

Of 110 patients that were included in the statistical analysis, $40 \%$ (44 of 110 patients) received pyloromyotomy and $60 \%$ (66 of 110 patients) did not receive pyloromyotomy prior to the creation of the duodenojejunostomy. Baseline demographics and clinical characteristics were similar between the two groups (Table 1).

\section{Delayed gastric emptying}

In the study population, DGE of any grade was present in 62 patients $(56.4 \%)$. The rate of DGE was $40.9 \%$ in the PM group (18 of 44 patients) and $66.7 \%$ in the NP group (44 of 66 patients). Patients who underwent pyloromyotomy had a lower risk for DGE in univariate analysis (OR $0.315,95 \% \mathrm{CI}$ $0.16-0.76 ; P=0.008)$. Grade A DGE was the most common type of DGE followed by grades B and C. The distribution of DGE grades did not differ significantly between the $\mathrm{PM}$ and NP groups $(P=0.465)$. Grades A and $\mathrm{C}$ were more common in the NP group (PM $22.7 \%$ vs. NP $39.4 \%$ and PM $4.5 \%$ vs. NP $13.6 \%$, respectively) whereas grade B was equally

Table 1 Demographics and clinical characteristics

\begin{tabular}{llll}
\hline Characteristic & $\mathrm{PM}(n=44)$ & $\mathrm{NP}(n=66)$ & $P$ \\
\hline Sex, $n(\%)$ & & & \\
$\quad$ Female & $22(50.0 \%)$ & $29(43.9 \%)$ & 0.532 \\
$\quad$ Male & $22(50.0 \%)$ & $37(56.1 \%)$ & \\
BMI $\geq 30 \mathrm{~kg} / \mathrm{m}^{2}, n(\%)$ & $3(6.8 \%)$ & $9(13.6 \%)$ & 0.356 \\
Chronic renal insufficiency, $n(\%)$ & $7(15.9 \%)$ & $8(12.1 \%)$ & 0.571 \\
Diabetes mellitus, $n(\%)$ & $8(18.2 \%)$ & $13(19.7 \%)$ & 0.843 \\
Previous abdominal surgery, $n(\%)$ & $15(34.1 \%)$ & $21(31.8 \%)$ & 0.803 \\
ASA, $n(\%)$ & & & \\
I & $2(4.5 \%)$ & $4(6.1 \%)$ & 0.621 \\
II & $22(50.0 \%)$ & $28(42.4 \%)$ & \\
III & $20(45.5 \%)$ & $34(51.5 \%)$ & \\
Histology, $n(\%)$ & & & \\
Malignant & $37(84.1 \%)$ & $58(87.9 \%)$ & 0.571 \\
Benign & $7(15.9 \%)$ & $8(12.1 \%)$ & \\
Age & $69.6 \pm 10.8$ & $68.8 \pm 11.6$ & 0.802 \\
\hline
\end{tabular}

Data are mean $\pm \mathrm{SD}$ or $n(\%)$

$P M$ pyloromyotomy, $N P$ no pyloromyotomy, $B M I$ body mass index, $A S A$ American Society of Anesthesiologists 
common in both groups (13.6\%). The intraoperatively placed NGT was required for a shorter duration $(P=0.019)$ in the PM group (mean 1.49 days) compared with the NP group (mean 4.11 days). In the PM group, 7 patients (15.9\%) required reinsertion of the NGT whereas 15 patients $(22.7 \%)$ required reinsertion in the NP group $(P=0.381)$. The outcomes are shown in Table 2.

\section{Secondary outcomes and complications}

Operating time was significantly lower in the PM group (PM: median 258 min vs. NP: median $312 \mathrm{~min}$; $P<0.001)$. Reoperation rates were similar between both groups (PM, 6 of $44 ; 13.6 \%$ vs. NP, 10 of $66 ; 15.2 \%$; $P=$ $0.825)$. There was no difference in intraoperative blood loss $(P=0.150)$ and length of hospital stay $(P=0.150)$ between both groups.

Postoperative complications are shown in Table 3. The overall in-hospital mortality rate in the study population was $2.7 \%$ ( 3 of 110 patients) with no difference between both groups $(P=0.273)$. Relaparotomy was performed in 15 of 110 patients (five cases of postoperative hemorrhage, four cases of pancreatic fistula grade $\mathrm{C}$, two cases of bile leak, two cases of wound dehiscence, and one case of exploratory laparotomy). In the overall population, 38 of 110 patients $(34.5 \%)$ developed an intra-abdominal complication. Intra-abdominal complication rates and major complications (Clavien-Dindo III or higher) did not differ between the PM and NP groups $(P=0.368$ and $P=0.190)$. All other complications did not differ between both groups (Table 3).

\section{Risk factors for DGE and multivariate analysis}

Demographic factors and early postoperative complications with potential association with DGE $(P<0.15$ in univariate analysis) were tested for association with DGE (Table 4). The presence of an intra-abdominal complication showed a strong association with the occurrence of DGE in univariate analysis (OR 7.38, 95\% CI 2.58-21.16; $P<0.001)$ and remained an independent risk factor for DGE even after correcting for the intraoperative handling of the pyloric muscle (OR 5.54, 95\% CI 2.00-15.36; $P=0.001$ ). Pyloromyotomy was associated with a risk reduction for DGE in the multivariate analysis (OR $0.32,95 \%$ CI 0.13 $0.77 ; P=0.011)$.

Since we noticed a significant difference in operating time between the PM and NP groups, we performed an additional multivariate analysis with the inclusion of the potential risk factor operating time. Despite the inclusion of operating time in the multivariate analysis, pyloromyotomy remained associated with a reduced risk for DGE (OR 0.36 , 95\% CI 0.14-0.92; $P=0.032$ ). Operating time itself was not associated with DGE in multivariate analysis $(P=0.36)$.

In order to assess the rate of DGE in the absence of an intra-abdominal complication, which is also referred to as primary DGE, we performed a subgroup analysis of the 72 patients without an intra-abdominal complication. The overall rate of DGE was $43.1 \%$ (31 of 72 patients) within the subgroup. In the PM group, $29.0 \%$ of patients ( 9 of 31 patients) compared with $53.7 \%$ (22 of 41 patients) in the NP group developed a DGE (OR 0.35, 95\% CI 0.13-0.95; $P=0.037)$.

\begin{tabular}{lllr}
\hline Characteristic & PM $(n=44)$ & NP $(n=66)$ & $P$ \\
\hline DGE, $n(\%)$ & $18(40.9 \%)$ & $44(66.7 \%)$ & 0.008 \\
DGE grade*, $n(\%)$ & & & \\
A & $10(22.7 \%)$ & $26(39.4 \%)$ & 0.465 \\
B & $6(13.6 \%)$ & $9(13.6 \%)$ & \\
C & $2(4.5 \%)$ & $9(13.6 \%)$ & 0.272 \\
DGE grades B and C only, $n(\%)$ & $8(18.2 \%)$ & $18(27.3 \%)$ & $<0.001$ \\
Operating time, median (IQR) (min) & $258(220-290)$ & $312(268-353)$ & 0.150 \\
Estimated blood loss, median (IQR) (mL) & $450(300-675)$ & $600(400-1000)$ & 0.019 \\
Removal of the first NGT (days) & $1.49 \pm 1.6$ & $4.11 \pm 9.5$ & 0.108 \\
Solid food intake (days) & $9.4 \pm 5.9$ & $12.6 \pm 12.8$ & 0.381 \\
Reinsertion of NGT, $n(\%)$ & $7(15.9 \%)$ & $15(22.7 \%)$ & 0.571 \\
Reoperation, $n$ (\%) & $5(11.4 \%)$ & $10(15.2 \%)$ & 0.150 \\
Postoperative stay (days) & $20.4 \pm 9.9$ & $24.1 \pm 14.5$ & \\
\hline
\end{tabular}

Data are mean $\pm \mathrm{SD}$ or $n(\%)$ or median (IQR)

$P M$ pyloromyotomy, $N P$ no pyloromyotomy, $D G E$ delayed gastric emptying, $N G T$ nasogastric tube, IQR interquartile range, $S D$ standard deviation

*Only patients with DGE are included in the analysis 
Table 3 Postoperative complications

\begin{tabular}{llll}
\hline Characteristic & PM $(n=44)$ & NP $(n=66)$ & $P$ \\
\hline In-hospital mortality, $n(\%)$ & $0(0 \%)$ & $3(4.5 \%)$ & 0.273 \\
Intra-abdominal complication, $n(\%)$ & $13(29.5 \%)$ & $25(37.9 \%)$ & 0.368 \\
Complication Clavien-Dindo III or higher, $n(\%)$ & $9(20.5 \%)$ & $21(31.8 \%)$ & 0.190 \\
Biochemical leak, $n(\%)$ & 0 & $3(4.5 \%)$ & 0.273 \\
POPF, $n(\%)$ & $6(13.6 \%)$ & $8(12.1 \%)$ & 0.815 \\
Grade B, $n(\%)$ & $4(9.1 \%)$ & $5(7.6 \%)$ & 1.00 \\
Grade C, $n(\%)$ & $2(4.5 \%)$ & $3(4.5 \%)$ & 1.00 \\
Intra-abdominal fluid collection, $n(\%)$ & $2(4.5 \%)$ & $3(4.5 \%)$ & 1.00 \\
Bile leak, $n(\%)$ & $3(6.8 \%)$ & $5(7.6 \%)$ & 1.00 \\
Chyle leak, $n$ (\%) & $2(4.5 \%)$ & $1(1.5 \%)$ & 0.563 \\
Postoperative hemorrhage, $n(\%)$ & $5(11.4 \%)$ & $8(12.1 \%)$ & 0.904 \\
Leakage of duodenojejunostomy, $n(\%)$ & $0(0 \%)$ & $1(1.5 \%)$ & 1.00 \\
Pulmonary aspiration and pneumonia, $n(\%)$ & $0(0 \%)$ & $4(6.1 \%)$ & 0.148 \\
Pulmonary embolism, $n(\%)$ & $0(0 \%)$ & $1(1.5 \%)$ & 1.00 \\
Surgical site infection, $n(\%)$ & $3(6.8 \%)$ & $7(10.6 \%)$ & 0.737 \\
Wound dehiscence, $n(\%)$ & $1(2.3 \%)$ & $2(3.0 \%)$ & 1.00 \\
Portal vein thrombosis, $n(\%)$ & $1(2.3 \%)$ & $2(3.0 \%)$ & 1.00 \\
Urinary tract infection, $n(\%)$ & $0(0 \%)$ & $3(4.5 \%)$ & 0.273 \\
Liver failure, $n(\%)$ & $0(0 \%)$ & $1(1.5 \%)$ & 1.00 \\
NSTEMI, $n(\%)$ & $0(0 \%)$ & $1(1.5 \%)$ & 1.00 \\
\hline
\end{tabular}

Data are $n(\%)$

$P M$ pyloromyotomy, $N P$ no pyloromyotomy, $P O P F$ postoperative pancreatic fistula, NSTEMI non-ST elevation myocardial infarction

\section{Discussion}

This retrospective analysis showed a significant difference in DGE rates between patients in whom an intraoperative pyloromyotomy was performed and patients who did not receive an intraoperative pyloromyotomy. We did not notice any complications in this study resulting directly from the incision of the pyloric muscle such as bleeding from the pyloric muscle. The overall rate of DGE in this series was $56.9 \%$ and on the higher end of the reported range of DGE rates but is in line with DGE rates from prospective trials $[5,6,16]$ underlining that DGE is a frequent and burdening complication after PD. Although we did not apply a standardized protocol for postoperative return to an oral diet at the time of the study, it was common practice to remove the NGT if no or limited reflux was present and return to a liquid diet followed by a solid diet as soon as clinically feasible.

Intra-abdominal complications were strongly associated with DGE and remained an independent risk factor even after correction for the surgical approach. Postoperative intraabdominal complications have been previously discussed as a possible causal factor in the development of DGE [20,29]. Some authors even suggested to distinguish between "primary DGE" in the absence of intra-abdominal complications and DGE accompanied by complications [5]. Therefore, we performed a subgroup analysis in order to get a better understanding of the effect of our surgical modification. Among patients without any intra-abdominal complications, we also found a reduced risk for DGE in patients who underwent pyloromyotomy (OR $0.35,95 \%$ CI $0.13-0.95 ; P=0.037$ ).

The concept of pyloromyotomy for the reduction of DGE in ppPD has been studied previously. Kim et al. [16] performed a Fredet-Ramstedt-type pyloromyotomy in combination with an antroplasty [30] in a series of 47 consecutive ppPD patients. They reported a DGE incidence of $2.2 \%$ with DGE defined as an inability to tolerate any oral intake including a liquid diet for three consecutive days in the absence of any attributable complications. Although the low incidence in the series by Kim et al. can be partially explained with the strict individual definition of DGE, a comparison to patients from the same institution treated before the introduction of the Fredet-Ramstedt pyloromyotomy by the same authors showed a reduction in DGE rates with pyloromyotomy. Additionally, the successful treatment of gastroparesis with underlying increased pyloric tone and pylorospasm with peroral endoscopic endoluminal pyloromyotomy [31-33] supports the idea to apply an intraoperative pyloromyotomy for the reduction of DGE.

Two Japanese trials and one German randomized controlled trial investigated the association between pyloric 
Table 4 Risk factors and protective factors for DGE

\begin{tabular}{|c|c|c|c|c|c|}
\hline Variable & $\begin{array}{l}\text { DGE } \\
(n=62 ; 56.4 \%)\end{array}$ & $\begin{array}{l}\text { No DGE } \\
(n=48 ; 43.6 \%)\end{array}$ & $\begin{array}{l}\text { Univariable } \\
P\end{array}$ & $\begin{array}{l}\text { Multivariable } \\
\text { OR }(95 \% \mathrm{CI})\end{array}$ & $\begin{array}{l}\text { Multivariable } \\
P\end{array}$ \\
\hline Age & $69.8(10.8)$ & $68.2(11.1)$ & 0.323 & - & \\
\hline Diabetes mellitus, $n(\%)$ & $11(17.7 \%)$ & $10(20.8 \%)$ & 0.682 & - & \\
\hline Female*, $n(\%)$ & $31(50 \%)$ & $20(41.7 \%)$ & 0.385 & $1.86(0.76-4.55)$ & 0.175 \\
\hline $\mathrm{BMI} \geq 30 \mathrm{~kg} / \mathrm{m}^{2}, n(\%)$ & $9(14.5 \%)$ & $3(6.3 \%)$ & 0.168 & $1.71(0.38-7.69)$ & 0.485 \\
\hline ASA III or higher, $n(\%)$ & $29(46.8 \%)$ & $25(52.1 \%)$ & 0.581 & - & \\
\hline Chronic renal insufficiency, $n(\%)$ & $11(17.7 \%)$ & $4(8.3 \%)$ & 0.154 & - & \\
\hline Previous abdominal surgery, $n(\%)$ & $21(33.9 \%)$ & $15(31.3 \%)$ & 0.771 & - & \\
\hline Malignant disease*, $n(\%)$ & $54(87.1 \%)$ & $41(85.4 \%)$ & 0.799 & $1.21(0.35-4.24)$ & 0.767 \\
\hline Chyle leak, $n(\%)$ & $2(3.2 \%)$ & $1(2.1 \%)$ & 1.00 & - & \\
\hline Intra-abdominal fluid collection, $n(\%)$ & $2(3.2 \%)$ & $3(6.3 \%)$ & 0.651 & - & \\
\hline POPF, $n(\%)$ & $11(17.7 \%)$ & $3(6.3 \%)$ & 0.073 & $2.60(0.52-13.04)$ & 0.246 \\
\hline Intra-abdominal complication, $n(\%)$ & $31(50.0 \%)$ & $7(14.6 \%)$ & $<0.001$ & $5.54(2.00-15.36)$ & 0.001 \\
\hline Pyloromyotomy performed, $n(\%)$ & $18(29.0 \%)$ & $26(54.2 \%)$ & 0.008 & $0.32(0.13-0.77)$ & 0.011 \\
\hline
\end{tabular}

Data are mean $\pm \mathrm{SD}$ or $n(\%)$

$D G E$ delayed gastric emptying, $B M I$ body mass index, $A S A$ American Society of Anesthesiologists, $P O P F$ postoperative pancreatic fistula

*Additionally included in multivariate analysis because of association with DGE in multivariate analysis of prospective studies [10, 13, 20, 28]

resection and DGE. Kawai et al. [34] found a significant reduction in DGE incidence between pylorus-resecting and pylorus-preserving pancreaticoduodenectomy $(4.5 \%$ vs. $17.2 \% ; P=0.02$ ). Matsumoto et al. [35] excluded patients with pancreatic cancer from the trial and did not find an association between pylorus resection and incidence of DGE. The PROPP trial by Hackert et al. [20] which represents the most recent and largest RCT investigating the effect of pylorus resection did not find a difference in DGE incidence or severity between the two groups. The results from the PROPP trial argue against pyloric dysfunction as the main mechanism in the development of DGE and favor a multifactorial etiology. Arguably, the results from the PROPP trial partially question the concept of pyloromyotomy for the reduction of DGE which is largely based on the idea of a postoperative impaired pyloric function. These conflicting results underline our incomplete understanding of the etiology of DGE, and further research is required to fully elucidate the mechanisms causing postoperative DGE.

As with most retrospective studies, this study has several limitations. These include incomplete documentation, interpretation bias, and variability in the clinical management of patients in the postoperative period. The fact that pyloromyotomy was performed at the discretion of the surgeon in charge might have introduced a performance bias since the participating surgeons had different levels of training. Approximately one-third of participating surgeons mostly performed pyloromyotomy while two-thirds preferred to apply stretching to the pyloric muscle. A difference in operating times between the PM and NP groups might be an indication of a higher level of training in the PM group, but operating time was not associated with DGE in the multivariate analysis.

\section{Conclusion}

Despite limitations, this study delivered positive results for a simple technique that could potentially lower the incidence of DGE after PD. These results encouraged us to further investigate our findings and the impact of intraoperative pyloromyotomy on DGE and quality of life in a randomized prospective study which has been registered at the German Registry of Clinical Trials (DRKS Nr. 00013503) and is currently enrolling patients.

Funding Open Access funding enabled and organized by Projekt DEAL.

\section{Compliance with ethical standards}

Conflict of interest The authors declare that they have no conflict of interest.

Open Access This article is licensed under a Creative Commons Attribution 4.0 International License, which permits use, sharing, adaptation, distribution and reproduction in any medium or format, as long as you give appropriate credit to the original author(s) and the source, provide a link to the Creative Commons licence, and indicate if changes were made. The images or other third party material in this article are included in the article's Creative Commons licence, unless indicated otherwise in a credit line to the material. If material is not included in the article's Creative Commons licence and your intended use is not permitted by 
statutory regulation or exceeds the permitted use, you will need to obtain permission directly from the copyright holder. To view a copy of this licence, visit http://creativecommons.org/licenses/by/4.0/.

\section{References}

1. Traverso LW, Longmire WP Jr (1978) Preservation of the pylorus in pancreaticoduodenectomy. Surg Gynecol Obstet 146(6):959962

2. Huttner FJ, Fitzmaurice C, Schwarzer G, Seiler CM, Antes G, Buchler MW, Diener MK (2016) Pylorus-preserving pancreaticoduodenectomy ( $p$ p Whipple) versus pancreaticoduodenectomy (classic Whipple) for surgical treatment of periampullary and pancreatic carcinoma. Cochrane Database Syst Rev 2(5):CD006053

3. Hill JS, Zhou Z, Simons JP, Ng SC, McDade TP, Whalen GF, Tseng JF (2010) A simple risk score to predict in-hospital mortality after pancreatic resection for cancer. Ann Surg Oncol 17(7):18021807

4. Fernandez-del Castillo C, Morales-Oyarvide V, McGrath D, Wargo JA, Ferrone CR, Thayer SP, Lillemoe KD, Warshaw AL (2012) Evolution of the Whipple procedure at the Massachusetts General Hospital. Surgery 152(3 Suppl 1):S56-S63

5. Eshuis WJ, van Eijck CH, Gerhards MF, Coene PP, de Hingh IH, Karsten TM, Bonsing BA, Gerritsen JJ, Bosscha K, Spillenaar Bilgen EJ, Haverkamp JA, Busch OR, van Gulik TM, Reitsma JB, Gouma DJ (2014) Antecolic versus retrocolic route of the gastroenteric anastomosis after pancreatoduodenectomy: a randomized controlled trial. Ann Surg 259(1):45-51

6. Eshuis WJ, de Bree K, Sprangers MAG, Bennink RJ, van Gulik TM, Busch ORC, Gouma DJ (2015) Gastric emptying and quality of life after pancreatoduodenectomy with retrocolic or antecolic gastroenteric anastomosis. Br J Surg 102(9):1123-1132

7. Eisenberg JD, Rosato EL, Lavu H, Yeo CJ, Winter JM (2015) Delayed gastric emptying after pancreaticoduodenectomy: an analysis of risk factors and cost. J Gastrointest Surg 19(9):1572-1580

8. Warshaw AL, Torchiana DL (1985) Delayed gastric emptying after pylorus-preserving pancreaticoduodenectomy. Surg Gynecol Obstet 160(1):1-4

9. Wente MN, Bassi C, Dervenis C, Fingerhut A, Gouma DJ, Izbicki JR, Neoptolemos JP, Padbury RT, Sarr MG, Traverso LW, Yeo CJ, Buchler MW (2007) Delayed gastric emptying (DGE) after pancreatic surgery: a suggested definition by the International Study Group of Pancreatic Surgery (ISGPS). Surgery 142(5):761-768

10. Welsch T, Borm M, Degrate L, Hinz U, Buchler MW, Wente MN (2010) Evaluation of the International Study Group of Pancreatic Surgery definition of delayed gastric emptying after pancreatoduodenectomy in a high-volume centre. Br J Surg 97(7): $1043-1050$

11. Yeo CJ, Barry MK, Sauter PK, Sostre S, Lillemoe KD, Pitt HA, Cameron JL (1993) Erythromycin accelerates gastric emptying after pancreaticoduodenectomy. A prospective, randomized, placebocontrolled trial. Ann Surg 218(3):229-237 discussion 237-228

12. Qu H, Sun GR, Zhou SQ, He QS (2013) Clinical risk factors of delayed gastric emptying in patients after pancreaticoduodenectomy: a systematic review and meta-analysis. Eur J Surg Oncol 39(3):213-223

13. Park JS, Hwang HK, Kim JK, Cho SI, Yoon DS, Lee WJ, Chi HS (2009) Clinical validation and risk factors for delayed gastric emptying based on the International Study Group of Pancreatic Surgery (ISGPS) classification. Surgery 146(5):882-887
14. Parmar AD, Sheffield KM, Vargas GM, Pitt HA, Kilbane EM, Hall BL, Riall TS (2013) Factors associated with delayed gastric emptying after pancreaticoduodenectomy. HPB (Oxford) 15(10):763772

15. Fischer CP, Hong JC (2006) Method of pyloric reconstruction and impact upon delayed gastric emptying and hospital stay after pylorus-preserving pancreaticoduodenectomy. J Gastrointest Surg 10(2):215-219

16. Kim DK, Hindenburg AA, Sharma SK, Suk CH, Gress FG, Staszewski H, Grendell JH, Reed WP (2005) Is pylorospasm a cause of delayed gastric emptying after pylorus-preserving pancreaticoduodenectomy? Ann Surg Oncol 12(3):222-227

17. Ohtsuka T, Takahata S, Ohuchida J, Takeda T, Matsunaga $\mathrm{H}$, Yokohata K, Yamaguchi K, Chijiiwa K, Tanaka M (2002) Gastric phase 3 motility after pylorus-preserving pancreatoduodenectomy. Ann Surg 235(3):417-423

18. Takahata S, Ohtsuka T, Nabae T, Matsunaga H, Yokohata K, Yamaguchi K, Chijiiwa K, Tanaka M (2002) Comparison of recovery of gastric phase III motility and gastric juice output after different types of gastrointestinal reconstruction following pyloruspreserving pancreatoduodenectomy. J Gastroenterol 37(8):596603

19. Gauvin JM, Sarmiento JM, Sarr MG (2003) Pylorus-preserving pancreaticoduodenectomy with complete preservation of the pyloroduodenal blood supply and innervation. Arch Surg 138(11):1261-1263

20. Hackert T, Probst P, Knebel P, Doerr-Harim C, Bruckner T, Klaiber U, Werner J, Schneider L, Michalski CW, Strobel O, Ulrich A, Diener MK, Buchler MW (2018) Pylorus resection does not reduce delayed gastric emptying after partial pancreatoduodenectomy: a blinded randomized controlled trial (PROPP study, DRKS00004191). Ann Surg 267(6):1021-1027

21. Huttner FJ, Klotz R, Ulrich A, Buchler MW, Diener MK (2016) Antecolic versus retrocolic reconstruction after partial pancreaticoduodenectomy. Cochrane Database Syst Rev 9(9): CD011862

22. Kurahara H, Shinchi H, Maemura K, Mataki Y, Iino S, Sakoda M, Ueno S, Takao S, Natsugoe S (2011) Delayed gastric emptying after pancreatoduodenectomy. J Surg Res 171(2):e187-e192

23. Hanna MM, Tamariz L, Gadde R, Allen C, Sleeman D, Livingstone A, Yakoub D (2016) Delayed gastric emptying after pylorus preserving pancreaticoduodenectomy - does gastrointestinal reconstruction technique matter? Am J Surg 211(4):810-819

24. Qian D, Lu Z, Jackson R, Wu J, Liu X, Cai B, Wu P, Yin J, Xu Q, Xu D, Peng Y, Jiang K, Miao Y (2016) Effect of antecolic or retrocolic route of gastroenteric anastomosis on delayed gastric emptying after pancreaticoduodenectomy: a meta-analysis of randomized controlled trials. Pancreatology 16(1):142-150

25. Klaiber U, Probst P, Strobel O, Michalski CW, Dorr-Harim C, Diener MK, Buchler MW, Hackert T (2018) Meta-analysis of delayed gastric emptying after pylorus-preserving versus pylorusresecting pancreatoduodenectomy. Br J Surg 105(4):339-349

26. Dindo D, Demartines N, Clavien PA (2004) Classification of surgical complications: a new proposal with evaluation in a cohort of 6336 patients and results of a survey. vol 240

27. Bassi C, Marchegiani G, Dervenis C, Sarr M, Abu Hilal M, Adham M, Allen P, Andersson R, Asbun HJ, Besselink MG, Conlon K, Del Chiaro M, Falconi M, Fernandez-Cruz L, Fernandez-Del Castillo C, Fingerhut A, Friess H, Gouma DJ, Hackert T, Izbicki J, Lillemoe KD, Neoptolemos JP, Olah A, Schulick R, Shrikhande SV, Takada T, Takaori K, Traverso W, Vollmer CR, Wolfgang CL, Yeo CJ, Salvia R, Buchler M (2017) The 2016 update of the International Study Group (ISGPS) definition and grading of postoperative pancreatic fistula: 11 years after. Surgery 161(3):584-591

28. Riediger H, Makowiec F, Schareck WD, Hopt UT, Adam U (2003) Delayed gastric emptying after pylorus-preserving 
pancreatoduodenectomy is strongly related to other postoperative complications. J Gastrointest Surg 7(6):758-765

29. Robinson JR, Marincola P, Shelton J, Merchant NB, Idrees K, Parikh AA (2015) Peri-operative risk factors for delayed gastric emptying after a pancreaticoduodenectomy. HPB (Oxford) 17(6): 495-501

30. Fonkalsrud EW, Ament ME, Vargas J (1992) Gastric antroplasty for the treatment of delayed gastric emptying and gastroesophageal reflux in children. Am J Surg 164(4):327-331

31. Geyl S, Legros R, Charissou A, Mesturoux L, Couquet C-Y, Carrier P, Brayette A, El-Ouafi Z, Loustaud-Ratti V, Sautereau D, Monteil J, Jacques J (2016) Peroral endoscopic pyloromyotomy accelerates gastric emptying in healthy pigs: proof of concept. Endosc Int Open 4(7):E796-E799

32. Su A, Conklin JL, Sedarat A (2018) Endoscopic therapies for gastroparesis. Curr Gastroenterol Rep 20(6):25

33. Grover M, Farrugia G, Stanghellini V (2019) Gastroparesis: a turning point in understanding and treatment. Gut 68:2238-2250
34. Kawai M, Tani M, Hirono S, Miyazawa M, Shimizu A, Uchiyama $\mathrm{K}$, Yamaue $\mathrm{H}$ (2011) Pylorus ring resection reduces delayed gastric emptying in patients undergoing pancreatoduodenectomy: a prospective, randomized, controlled trial of pylorus-resecting versus pylorus-preserving pancreatoduodenectomy. Ann Surg 253(3): 495-501

35. Matsumoto I, Shinzeki M, Asari S, Goto T, Shirakawa S, Ajiki T, Fukumoto T, Suzuki Y, Ku Y (2014) A prospective randomized comparison between pylorus- and subtotal stomach-preserving pancreatoduodenectomy on postoperative delayed gastric emptying occurrence and long-term nutritional status. J Surg Oncol 109(7): 690-696

Publisher's note Springer Nature remains neutral with regard to jurisdictional claims in published maps and institutional affiliations. 